\title{
CLASS I AND CLASS II ANTI-HLA ANTIBODIES AFTER IMPLANTATION OF CRYOPRESERVED ALLOGRAFT MATERIAL IN PEDIATRIC PATIENTS
}

John A. Hawkins, MD

John P. Breinholt, MD

Linda M. Lambert, BSN

Thomas C. Fuller, PhD

Tracie Profaizer, BS

Edwin C. McGough, MD

Robert E. Shaddy, MD
Objectives: Very little is known regarding the immune response to cryopreserved allograft valves and patch material used in the surgical repair of congenital heart defects. Methods: We prospectively measured the frequency of panel reactive antibodies directed against HLA class I (HLA$A, B$, and C) and class II (HLA-DR/DQ) alloantigens in 24 children receiving cryopreserved allografts. We compared them with results in 11 previously reported control patients. Sixteen of the study patients underwent placement of a valved conduit (11 pulmonic, 5 aortic) between the right ventricle and pulmonary arteries, 6 underwent patch angioplasty of stenotic vessels with cryopreserved pulmonary artery, and 2 underwent placement of a pulmonary monocusp patch. Study patients had panel reactive antibodies measured before, 1 month, 3 months, and 1 year after the operation. Results: With allograft implantation, panel reactive antibodies increased from $1.9 \% \pm 5 \%$ before the operation to $62 \% \pm 33 \%$ at $31 \pm 8$ days after the operation, $92 \% \pm 15 \%$ at $3.3 \pm 0.6$ months after the operation, and $85 \% \pm 18 \%$ at $1.1 \pm 0.2$ years after the operation. The control group showed no change in panel reactive antibodies, with a level of $1.6 \% \pm 1 \%$ before the operation, $3.2 \% \pm$ $1 \% 28 \pm 5$ days after the operation, and $1.7 \% \pm 1 \% 2.7 \pm 0.3$ months after the operation. Class II antibodies (anti-HLA-DR/DQ) rose to $49 \%$ $\pm 35 \%$ at $30 \pm 8$ days and $70 \% \pm 26 \%$ at $3.3 \pm 0.6$ months after the operation. Conclusions: Cryopreserved allograft material induces a marked response that involves both class I and class II anti-HLA antibodies within 3 months after operation in children. This alloantibody response may represent a form of "rejection," may have implications for those who require subsequent cardiac transplantation, and may play a role in early allograft failure. (J Thorac Cardiovasc Surg 2000;119:324-30)
$\mathrm{C}$ ryopreserved human allograft material has been extensively used over the past decade to reconstruct a variety of congenital cardiac defects. Although valved allografts have been the most commonly used material, cryopreserved allograft patches and monocusp pul-

From the Departments of Surgery, Pathology, and Pediatrics, Primary Children's Medical Center and the University of Utah, Salt Lake City, Utah.

Read at the Twenty-fifth Annual Meeting of The Western Thoracic Surgical Association, Olympic Valley (Lake Tahoe), Calif, June 23-26, 1999.

Received for publication June 29, 1999; revisions requested Sept 7, 1999; revisions received Oct 12, 1999; accepted for publication Oct 28, 1999.

Address for reprints: John A. Hawkins, MD, Pediatric Cardiothoracic Surgery, Primary Children's Medical Center, 100 North Medical Dr, Salt Lake City, UT 84113 (E-mail: jhawkins@ @ed.utah.edu). Copyright (C) 2000 by Mosby, Inc.

$0022-5223 / 2000 \$ 12.00+0 \quad \mathbf{1 2 / 6 / 1 0 4 1 5 6}$ monary patches have also been extensively used in the reconstruction of the pulmonary arteries, aortic arch, and right ventricular outflow tract in children. Although their application has become widespread, very little is known about the immunogenicity of the implanted cryopreserved material or the role that immunologic "rejection" may play in the late functional results of cryopreserved allograft material. Because of the widespread use of cryopreserved allograft material, some awareness of the immunologic consequences of allograft implantation and the activation of anti-HLA antibodies has recently surfaced. ${ }^{1-3}$ No information is yet available on whether this antibody response causes late dysfunction of the allograft material, although if late cardiac transplantation is found necessary, persistent anti-HLA antibodies may affect application of this therapy.

This study was undertaken as an extension of a previous preliminary study ${ }^{3}$ in which we found that cryopre- 
served valved allografts elicit an anti-HLA antibody response. $\mathrm{We}^{4}$ previously found that this response is maximal 3 months after implantation, persists for at least 1 year, and involves class I HLA alloantibodies. The current study expands this preliminary study by prospectively examining both HLA class I and class II antibodies formed in response to cryopreserved allograft patch (nonvalved) material and pulmonary monocusp patches, in addition to cryopreserved valved allografts used in the reconstruction of a variety of congenital cardiac defects.

\section{Patients and methods}

Patients. We prospectively enrolled 24 patients in our study who received cryopreserved allograft material for reconstruction of congenital cardiac defects. Ages of the patients ranged from 7 days to 17 years (median 8.1 months) and weights ranged from 3.1 to $55 \mathrm{~kg}$ (median $7 \mathrm{~kg}$ ). Diagnoses and treatments are given in Table I. The types of allografts inserted included valved pulmonic allografts in 11, valved aortic allografts in 5, pulmonary artery patch (nonvalved) allograft in 6 , and pulmonary artery monocusp patch allograft in 2. Thirteen of the 24 patients receiving an allograft had undergone a previous open cardiac operation, all without previous allograft implantation.

Control patients included 11 patients undergoing open cardiac repair of congenital heart defects that did not require placement of any allograft material. These patients also had not had any previous allograft material implanted. Their ages ranged from 1 week to 13 years (median 22 months). Diagnoses for these control patients included ventricular septal defect in 4 patients, atrial septal defect in 4 patients, total anomalous pulmonary venous connection in 1 , pulmonary atresia with intact ventricular septum in 1 , and aortic stenosis in 1. Three of these patients had undergone previous cardiac surgery, but none had previous allograft material implanted.

Study methods. The study protocol was approved by the Institutional Review Board at Primary Children's Medical Center. Informed consent was obtained from the parents or guardian of each patient before entrance into the study. Blood was obtained for an HLA panel reactive antibody (PRA) at the following times: just before the operation, approximately 1 month after implantation of the allograft material, and approximately 3 months and 12 months after allograft implantation. All patients in both the study and control groups had blood products that had undergone both irradiation and leukocyte filtering to remove allogeneic white blood cells that could sensitize the patients. ${ }^{5}$ All blood products were irradiated with ${ }^{137} \mathrm{Cs}$ at $30 \mathrm{~Gy}$ and were filtered with Purecell leukocyte reduction filters (Pall Biomedical Products Co, East Hills, NY).

HLA-A, HLA-B, and HLA-C loci serotyping was performed on all patients by means of the standard complementdependent cytotoxicity (CDC) test and in-house serologic reagents. ${ }^{3}$ PRA was determined by means of the sensitive
Table I. Diagnoses and treatments in the 24 patients

\begin{tabular}{lc}
\hline & No. of patients \\
\hline Diagnosis & 5 \\
Truncus arteriosus & 3 \\
Tetralogy of Fallot with pulmonary atresia & 2 \\
Tetralogy of Fallot with severe pulmonary stenosis & 4 \\
Aortic stenosis with pulmonary valve replacement & \\
$\quad$ and concomitant Ross procedure & 2 \\
Pulmonary stenosis/insufficiency & 2 \\
Supravalvular pulmonary stenosis after & \\
$\quad$ arterial switch procedure & 1 \\
Tetralogy of Fallot with absent pulmonary valve & 2 \\
Recurrent aortic arch obstruction & 2 \\
Branch pulmonary artery stenosis/distortion & \\
$\quad$ with single ventricle & 1 \\
Corrected transposition with pulmonary stenosis & \\
Treatment & 11 \\
RV-PA valved allograft conduit & 5 \\
Orthotopic pulmonary valve insertion & 2 \\
Pulmonary artery monocusp insertion in RVOT & 4 \\
Pulmonary patch angioplasty & 2 \\
Allograft patch aortoplasty &
\end{tabular}

$R V$ - $P A$, Right ventricular-pulmonary artery; $R V O T$, right ventricular outflow tract.

anti-human kappa light-chain immunoglobulin cytotoxicity (AHG-CDC) technique against a frozen T-lymphocyte panel composed of 40 individuals of diverse HLA type and racial background. PRA was expressed as the percentage of lymphocyte panel members against which the patient's serum reacts and thus against which the patient has HLA class I antibody.

HLA-DR/DQ antibodies were evaluated by means of a previously reported flow cytometry techinique. ${ }^{6}$ This technique uses affinity-purified, soluble HLA-DR antigens from 30 different cell lines that are coupled individually to uniform latex beads and then pooled to create a panel that represents the majority of serologically recognized HLA-DR/DQ alloantigens (Flow-PRA II Beads; One Lambda, Canoga Park, Calif). After incubation of the beads with $0.02 \mathrm{~mL}$ of the patient's serum, washing and staining with saturating immunoglobulin $\mathrm{G}$ goat anti-human immunoglobulin $\mathrm{G}$, the percent fluorescent positive beads (class II percent PRA) was calculated after analysis on a Becton Dickinson FACScan flow cytometer (Becton Dickinson \& Co, Franklin Lakes, NJ).

Statistical analysis. Comparisons between continuous data were made with unpaired $t$ test or analysis of variance and the Scheffé post hoc analysis. All data were expressed as mean \pm standard deviation.

\section{Results}

Results are shown in Table II. Control patients had virtually no detectable levels of class I antibodies before the operation or 1 or 3 months after the operation. Because of this, we elected not to measure anti- 
Table II. Class I and class II alloantibody measurements in 24 patients after implantation of cryopreserved allograft material

Percent panel reactive HLA antibody \pm standard deviation

\begin{tabular}{|c|c|c|c|c|c|c|c|c|}
\hline \multirow{2}{*}{$\begin{array}{l}\text { Time after } \\
\text { allograft implant }\end{array}$} & \multicolumn{2}{|c|}{ Valved allografts $(n=16)$} & \multicolumn{2}{|c|}{ Allograft patch $(n=8)$} & \multicolumn{2}{|c|}{ Total group $(n=24)$} & \multicolumn{2}{|c|}{ Control group $(n=11)$} \\
\hline & $t$ Class I & Class II & Class I & Class II & Class I & Class II & Class I & Class II \\
\hline Preop & $2 \% \pm 6 \%$ & - & $0.4 \pm 1.1 \%$ & - & $1.5 \% \pm 5 \%$ & - & $2 \% \pm 1 \%$ & - \\
\hline $31 \pm 8 d$ & $69 \% \pm 35 \% *$ & $54 \% \pm 45 \%$ & $44 \% \pm 27 \%$ & $46 \% \pm 39 \%$ & $62 \% \pm 35 \% *$ & $49 \% \pm 38 \%$ & $3 \% \pm 1 \%$ & - \\
\hline $3.3 \pm 0.6 \mathrm{mo}$ & $98 \% \pm 3 \%{ }^{* \dagger}$ & $86 \% \pm 4 \%$ & $84 \% \pm 23 \% *$ & $58 \% \pm 31 \%$ & $92 \% \pm 15 \% * \|$ & $70 \% \pm 26$ & $2 \% \pm 1 \%$ & - \\
\hline $1.2 \pm 0.2 \mathrm{y}$ & $85 \% \pm 18 \% *$ & - & $85 \% \pm 22 \% 8$ & - & $85 \% \pm 18 \%^{* \dagger}$ & - & - & - \\
\hline
\end{tabular}

${ }^{*} P<.001$ versus preoperative value.

† $P=.003$ versus 1 month.

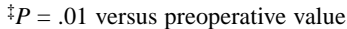

$\S_{P}=.02$ versus preoperative value.

" $P<.001$ versus 1 month.

bodies in the control group at 12 months. HLA class I antibodies increased significantly in study patients from minimal levels before the operation to significantly elevated levels by 1 month, maximal levels at 3 months, and persistently elevated levels at 1 year after implantation. Class II antibodies were also markedly elevated at 1 and 3 months after implantation. Class I antibodies tended to be lower in the patch group than the valved allograft group at the 1-month and 3-month intervals after implantation, but these differences did not reach statistical significance (Table II).

There were no differences in either class I or class II PRAs in infants less than 1 year of age as compared with children older than 1 year of age at any of the study times. Additionally, there were no differences in class I or class II PRAs for aortic allograft material as compared with pulmonary allograft material at any study time after the operation. The numbers of patients with allograft material implanted on the systemic side of the circulation $(\mathrm{n}=2)$ were insufficient to compare differences in PRA for allograft material implanted in the systemic circulation as compared with material implanted in the pulmonary circulation $(n=22)$. In addition, in the 12 patients in whom there was information on $\mathrm{ABO}$ typing for both the donor and recipient, 8 patient-allografts were $\mathrm{ABO}$ compatible and 4 were not. The class I antibody levels (PRA) were not significantly different at 1 month for $\mathrm{ABO}$ compatibility versus incompatibility $(69 \% \pm 25 \%$ vs $80 \% \pm 13 \%)$ or at 3 months $(85 \% \pm 23 \%$ vs $93 \% \pm 6 \%, P>.05)$.

\section{Discussion}

Cryopreserved allograft material has become very important in the definitive repair and palliation of a variety of congenital cardiac defects. Cryopreservation allows preservation of endothelial and valve architecture and viability with presumed improved durability and with the convenience of long-term storage. ${ }^{7}$ Unfortunately, better preservation of allograft and endothelium viability may actually sustain immunogenicity and elicit a more vigorous immunologic reaction from the recipient; this response can theoretically contribute to accelerated degeneration of allograft valves or patch material. Previous studies in human beings have demonstrated the presence of both class I and class II anti-HLA antibodies in patients after allograft implantation with homovital, antibiotic-preserved, and cryopreserved valved allografts..$^{2-4,8-11}$

This study demonstrates, in a prospective manner, that all cryopreserved allograft material (valves, monocusp patches, and nonvalved pulmonary allograft patches) elicits a strong immunologic response with the production of both class I and class II anti-HLA antibodies. This response is characterized by a brisk response within the first month, which persists up to 1 year (and maybe indefinitely) after implantation. Unique to our study is that we included a control group of children for comparison, removing the possibility that induction of these anti-HLA antibodies could be due to blood transfusion, cardiopulmonary bypass, or cardiac surgery. Moreover, both control and study patients underwent transfusion with blood products that were both leukopore filtered and irradiated to remove most leukocytes that may activate anti-HLA antibodies. ${ }^{5}$ Although some have suggested a more rapid deterioration of cryopreserved allografts in young infants and with aortic allograft material, ${ }^{12}$ we did not find any differences between these groups with respect to class I or class II PRA levels.

Although this study demonstrates the induction of 
anti-HLA antibodies in all allograft recipients, the question remains as to whether this represents a form of "rejection" analogous to that seen in solid organ transplantation. Implicit in any definition of rejection is not only a humoral or cellular immunologic response, but also some functional consequence of this immunologic reaction in the graft. No patient in this series has required reoperation to date and PRA has been elevated in all, so it is impossible to correlate the exact PRA level with the need for late reoperation or late functional results in our current study. Thus with PRA levels elevated in all all patients, the central question is what role these antibodies play in long-term allograft valve or patch function.

Antibody deposition and T-cell infiltrates have been previously demonstrated in pediatric valved conduits. ${ }^{9,12}$ Experimentally, cryopreserved aortic allograft patches (nonvalved) have been shown to contain adventitial inflammation and intimal thickening and infiltrates unrelated to the cryopreservation technique in both a rat ${ }^{13}$ and sheep model. ${ }^{14}$ Despite the fact that cryopreservation does contribute to some cell death in allografts, ${ }^{13,15,16}$ viable endothelium, fibroblasts, and dendritic cells have been demonstrated in cryopreserved allografts, some up to 9 years after the operation. ${ }^{7,15,16}$ The simple presence of an antigen protein on the allograft is not sufficient to induce an immunologic anti-HLA response; the induction of both humoral and cellular immunity also requires the presence of a live cell. ${ }^{17}$ This implies that the production of these class I and class II antibodies requires that there be some live cells in cryopreserved allografts; these allografts can be considered "transplants" in the broad sense of the word.

The relative absence of cellular infiltrates and structural abnormalities in valves after heart transplantation $^{18,19}$ implies that immunosuppression may help prevent some of the early failures seen in cryopreserved allografts implanted in infants and children. Experimentally, this has been shown in the rat model, with improvement in allograft valve survival resulting from treatment with cyclosporine A (INN: ciclosporin). ${ }^{20}$ Clinically, immunosuppression has been suggested and andecdotally tried in some children undergoing implantation of a cryopreserved allograft valve. ${ }^{21}$ Despite these experimental and theoretical advantages of immunosupression for cryopreserved allografts, there remains no hard evidence to date that routine immunosuppression will alter the antibody response and improve late allograft function in children.

Perhaps more important than the debate over the importance of immunologic factors in late function of cryopreserved allografts is the implications that these
anti-HLA antibodies have for future heart transplantation. Although most of these children would be anticipated to do well in the long term, some of them have significant heart disease or undergo palliative procedures that may be anticipated to require late transplantation. These may include patients with single ventricle physiology undergoing pulmonary artery reconstruction with allograft patches or children with hypoplastic left heart syndrome undergoing stage I palliation with a Norwood procedure. The presence of donor-specific HLA class I antibodies (PRA) has been demonstrated to increase the risk of acute or hyperacute cardiac allograft rejection and decrease graft survival. 22,23 Elevation of class II antibodies is also associated with an increased chance of hyperacute rejection in other areas of transplantation. ${ }^{24}$ In addition, elevation of PRA routinely requires prospective crossmatching before transplantation and will therefore decrease the available donor pool and increase waiting time. Although many may not be anticipated to need late cardiac transplantation, replacement of valved conduits will be very likely in the growing child. The presence of preformed antibodies to HLA antigens may cause an accelerated degeneration of future implanted valved allografts when conduits are replaced because of dysfunction or growth factors. Our study and those of others have demonstrated long-term persistence of these antibodies, up to 15 years after implantation in some cases. ${ }^{2}$

This study has several limitations that make it difficult to determine whether cryopreserved allografts undergo "rejection" similar to that seen in solid organ transplantation. We have demonstrated a definite humoral response in children receiving cryopreserved allografts, but we do not have any histologic or functional data to definitely make a diagnosis of "rejection." Some believe that immunology is unimportant in the long-term function of these cryopreserved allografts, ${ }^{18}$ but clearly the preponderance of evidence suggests the presence of an immunologic reaction that can be demonstrated histologically in some circumstances. ${ }^{2-4,7-12,14}$ It is also difficult to determine whether the elevated HLA class I and class II antibodies seen in this study are in response purely to HLA mismatches between donor and recipient. We did not make any attempt to match allograft material with the recipient with respect to $\mathrm{ABO}$ compatibility, but this should not have induced HLA antibodies since ABO incompatibilities are not accompanied by production of HLA antibodies. Some have suggested that ABO incompatibility elicits a stronger immunologic reaction with cryopreserved allografts, ${ }^{25}$ although previous clinical studies have suggested no functional difference in 
valved allografts when $\mathrm{ABO}$ compatibility is ignored. ${ }^{26,27}$ As suggested by Smith and associates, ${ }^{2}$ the only way this may be sorted out in the future is with better preoperative HLA and ABO matching of patient and allograft or perhaps the use of immunosuppression after the implantation of allograft material. In addition, follow-up in our study was relatively short, and we do not know how long these antibodies will persist or how they will actually affect later cardiac transplantation. It is presumed that these antibodies will persist for a significant period of time $^{2}$ because they are all immunoglobulin G HLA antibodies ${ }^{3,4}$; however, some anti-HLA antibodies that develop in response to blood transfusion in children can and do disappear over time. ${ }^{28}$ Only longer follow-up, prospective controlled studies, and better characterization of the humoral and cellular response will allow us to determine the specific effect these antibodies have on cryopreserved allografts and how we might alter them.

\section{REFERENCES}

1. Cochran RP, Kunzelman KS. Cryopreservation does not alter antigenic expression of aortic allografts. J Surg Res 1989;46:597-9.

2. Smith JD, Ogino H, Hunt D, Laylor RM, Rose ML, Yacoub MH. Humoral immune reponse to human aortic valve allografts. Ann Thorac Surg 1995;60:S127-30.

3. Shaddy RE, Hunter DD, Osborne KA, Lambert LM, Minich LL, Hawkins JA, et al. Prospective analysis of HLA immunogenicity of cryopreserved valved allografts used in pediatric heart surgery. Circulation 1996;94:1063-7.

4. Shaddy RE, Thompson DD, Osborne KA, Hawkins JA, Fuller TC. Persistence of human leukocyte antigen (HLA) antibodies after one year in children receiving cryopreserved valved allografts. Am J Cardiol 1997;80:358-9.

5. The Trial to Reduce Alloimmunization to Platelets Study Group. Leukocyte reduction and ultraviolet B irradiation of platelets to prevent alloimmunization and refractoriness to platelet transfusions. N Engl J Med 1997;337:1861-9.

6. Pei R, Wang G, Tarsitani C, Rojo S, Chen T, Takemura S, et al. Simultaneous HLA class I and class II antibodies screening with flow cytometry. Hum Immunol 1998;59:313-22.

7. O'Brien M, Stafford E, Gardner M, Pohlner P, McGiffin D. A comparison of aortic valve replacement with viable cryopreserved and fresh allograft valves with a note on chromosomal studies. J Thorac Cardiovasc Surg 1987;94:812-23.

8. Smith JD, Hornick PI, Rasmi N, Rose ML, Yacoub MH. Effect of HLA mismatching and antibody status on "homovital" aortic valve homograft performance. Ann Thorac Surg 1998;66:S212-5.

9. Hoekstra F, Knoop C, Vaessen L, Wassenaar C, Jutte N, Bos E, et al. Donor-specific cellular immune response against human cardiac valve allografts. J Thorac Cardiovasc Surg 1996;112:281-6.

10. Hoekstra F, Witvliet M, Knoop C, Akkersdijk G, Jutte N, Bogers A, et al. Donor-specific anti-human leukocyte antigen class I antibodies after implantation of cardiac valve allografts. J Heart Lung Transplant 1997;16:570-2.

11. Hoekstra FME, Witvliet M, Knoop CY, Wassenaar C, Bogers AJJC, Weimar W, Claas FHJ. Immunogenic human leukocyte antigen class II antigens on human cardiac valves induce specific alloantibodies. Ann Thorac Surg 1998;66:2022-6.

12. Rajani B, Mee RB, Ratliff NB. Evidence for rejection of homograft valves in infants. J Thorac Cardiovasc Surg 1998;115:111-7.

13. Motomura N, Imakita M, Yutani C, Kitoh Y, Kawashima Y, Oka T. Histological change in cryopreserved rat aortic allograft. J Cardiovasc Surg 1995;36:53-60.

14. Neves JP, Gulbenkian S, Ramos T, Martins AP, Caldas MC, Mascarenhas R, et al. Mechanisms underlying degeneration of cryopreserved vascular homografts. J Thorac Cardiovasc Surg 1997;113:1014-21.

15. Neves J, Monteiro C, Santos R, Martins A, Ramos S, Ramos T, et al. Histologic and genetic assessment of explanted allograft valves. Ann Thorac Surg 1995;60:S141-5.

16. O'Brien MF, Johnston N, Stafford G, Gardner M, Pohlner P, McGiffin D, et al. A study of the cells in the explanted viable cryopreserved allograft valve. J Card Surg 1988;3(suppl):279-87.

17. Batchelor JR, Welsh KI, Burgos H. Transplantation antigens per se are poor immunogens within a species. Nature 1978;273:546.

18. Mitchell RN, Jonas RA, Schoen FJ. Pathology of explanted cryopreserved allograft heart valves: comparison with aortic valves from orthotopic heart transplants. J Thorac Cardiovasc Surg 1998;115:118-27.

19. Valente M, Faggian G, Billingham ME, Talenti E, Calabrese F, Sasula R, et al. The aortic valve after heart transplantation. Ann Thorac Surg 1995;60:S135-40.

20. Yankah AC, Wottge HU, Muller-Rucholtz W. Short-course cyclosporine A therapy for definite allograft valve survival immunosuppression in allograft valve operations. Ann Thorac Surg 1995;60:S146-50.

21. Clarke DR, Campbell DN, Hayward AR, Bishop DA. Degeneration of aortic valve allografts in young recipients. $\mathrm{J}$ Thorac Cardiovasc Surg 1993;105:934-42.

22. Smith JD, Danskine AJ, Rose ML, Yacoub MH. Specificity of lymphocytotoxic antibodies formed after cardiac transplantation and correlation with rejection episodes. Transplantation 1992; 53:1358-62.

23. Suciu-Foca N, Reed E, Marboe C, Harris P, Yu PX, Sun YK, et al. The role of anti-HLA antibodies after heart transplantation. Transplantation 1991;51:716-24.

24. Ahern AT, Artruc SB, DellaPelle P, Cosimi AB, Russell PS, Colvin RB, et al. Hyperacute rejection of HLA-AB identical renal allografts associated with $\mathrm{B}$ lymphocyte and endothelial reactive antibodies. Transplantation 1982;33:103-6.

25. Fischlein T, Schutz A, Haushofer M, Frey R, Uhlig A, Detter C, et al. Immunologic reaction and viability of cryopreserved homografts. Ann Thorac Surg 1995;60:S122-6.

26. Shaddy RE, Tani LY, Sturtevant JE, Lambert LM, McGough EC. Effects of homograft blood type and anatomic type on stenosis, regurgitation and calcium in homografts in the pulmonary position. Am J Cardiol 1992;70:392-3.

27. Hawkins JA, Bailey WW, Dillon T, Schwartz DC. Midterm results with cryopreserved allograft valved conduits from the right ventricle to the pulmonary arteries. J Thorac Cardiovasc Surg 1992;104:910-6.

28. Scornik JC, Pfaff WW, Howard RJ, Fennell RS, Ramos E, Peterson JC, et al. Increased antibody responsiveness to blood transfusions in pediatric patients. Transplantation 1994;58:13615. 


\section{Discussion}

Dr David R. Clarke (Denver, Colo). I congratulate you on a very thought-provoking study. Let me be the first to agree with the proposed existence of an immune response to surgically implanted allografts in children. Because pediatric cardiac surgeons have come to rely on allograft valves, conduits, and tissues for surgical repair of numerous anomalies, a thorough understanding of allograft immunology becomes very important to optimize outcome. The remainder of my comments will be directed primarily toward outcome.

You have admitted that the duration of follow-up is short. What is the total follow-up (average and range) of these allograft recipients?

Dr Shaddy. The average follow-up is about $2 \frac{1}{2}$ years, with a range of 3 months to $4 \frac{1}{2}$ years.

Dr Clarke. Even in early follow-up in our clinical experience, tissue calcification and degeneration in both the left and right ventricular outflow tracts often results in homograft explantation, particularly in children who are 1 year of age or younger at initial implantation.

Acknowledging that there might be an anti-HLA antibody impact on late allograft dysfunction, has early degeneration or calcification occurred in your series? Even though you mentioned that none of the implants have been explanted, have you seen any evidence of early degeneration?

Dr Shaddy. Yes, we have seen a moderate amount of allograft dysfunction, and some of the stimulus for this work was the work that you had previously published on this problem in smaller children.

Dr Clarke. Is there any correlation between the PRA levels and the occurrence of this early degeneration?

Dr Shaddy. That is a very good question. Initially we had hoped to find a less brisk and a more varied response to these valved allografts or nonvalved allografts. Since all of the patients have such a strong response, and a very similar response, we are unable to differentiate between those who have early or late graft failure and those who do not. Some patients do very well, even some who have a very significant immune response, whereas others do not. As yet, we have not been able to discern the difference.

Dr Clarke. Have you been able to correlate any difference in the PRA response relative to the age of the patient at implantation?

Dr Shaddy. No, there has been no difference with regard to age. The younger children and the older children all had a very similar response that was present by 1 month and broadened in reactivity by 3 months.

Dr Clarke. In your study, 22 children had reconstruction of the right ventricular outflow tract and 2 had tissue implanted in the systemic circulation. Was there any difference in the response between those two locations? Did you note any difference between aortic and pulmonary allograft tissue when used in right ventricular outflow tract reconstructions?

Dr Shaddy. We have not been able to discern any difference between those groups.

Dr Clarke. In our series, as an alternative to immunosuppression, we have adopted a protocol to use anti-inflammato- ry treatment for the first 6 weeks after implantation of allografts. Have you used a similar protocol or have you noticed any difference in patients who were possibly treated for postpericardiotomy syndrome in terms of their development of PRA response?

Dr Shaddy. No, we have not.

Dr Clarke. In addition to the concern regarding the effect of these antibodies on long-term allograft function, the question is raised in your study about how this immunologic response might affect subsequent reaction to cardiac transplantation. We have an experience, although minimal, that may support this concern. Five children in our series have had allografts implanted and subsequently have undergone cardiac transplantation. In 2 of them the PRA levels were not known; one of these 2 patients is doing fine, and the other died of chronic rejection. The other 3 patients are very interesting. One of the children had a pretransplantation PRA of only $5 \%$ but died very shortly after his transplant operation, and we could not rule out hyperacute rejection. Another patient had a transplant $6 \frac{1}{2}$ years after allograft insertion. Initially he had a PRA of $90 \%$, but this dropped to $29 \%$ while he was on the waiting list; however, liver and kidney failure developed during that time, and he subsequently died 6 months after his cardiac transplantation, presumably of chronic rejection as well. A final child was pretreated with intravenous immunoglobulin and azathioprine, and this resulted in a drop in the PRA level from $96 \%$ to $12 \%$ at the time of cardiac transplantation $7 \frac{1}{2}$ years after his allograft implantation. That child is presently alive and doing very well.

Have you had similar experience with cardiac transplantation after allograft insertion?

Dr Shaddy. Anecdotally, we have. One of the other motivations for us to perform this study was the observation that 2 of our patients who had aortic reconstruction in the newborn period and subsequently required transplantation, both over a year after this initial procedure, had elevations in their PRA level. One of those patients had a positive crossmatch. This patient unfortunately died of unrelenting rejection after transplantation. Our experience may be similar to yours, although smaller, and this is part of the reason that we proceeded with the study. We are concerned that these preformed antibodies may become a problem in the small but significant number of patients who will subsequently require transplantation.

Dr Clarke. Perhaps in contrast we have evaluated our series of re-replacement of allografts with a second allograft. We looked at this in 35 children with an average follow-up of about 4 years and an overall follow-up of close to 8 years in the longest case. Event-free analysis of primary versus reoperative recipients shows that, at 7 years, $77 \%$ of reoperated survivors versus $69 \%$ of first-time allograft recipients are free from allograft replacement. Thus they are not statistically different. The similarity implies that this immunologic response may not affect reaction to subsequent allograft implants, although admittedly the follow-up is short. Do you have any experience that is similar?

Dr Shaddy. No, we do not have any experience with analyzing these patients, but that may be related to the short peri- 
od of follow-up in the current study. We have studied a few patients whose allograft implantation was done many years earlier, and we believe that the PRAs in some of these patients are going to decrease significantly over time. Perhaps they lose their immunoreactivity over time because there is not an ongoing stimulus. This may go along with pathologic findings that other investigators have reported, showing that, when removed, these grafts do not have inflammatory cells in them and do not appear to be undergoing rejection at that time. The reason may be that the rejection process has already been completed and the immunologic response then would have disappeared. Thus these patients may not be at risk for subsequent graft failure with reimplantation. That is only speculation.

Dr Vaughn A. Starnes (Los Angeles, Calif). Dr Shaddy, I have two comments and one question. The whole idea of immunologic reactivity has plagued transplantation for 25 years. There is no corelation between the immunoreactivity of our patients and transplantation. Many of these patients have highly reactive antibodies to the graft and have no $\mathrm{T}$ cell-mediated response. What you are seeing is a B cell-mediated response. I would caution people to take this information in context, because what we are interested in knowing is whether this is really a marker for ongoing or possible histologic damage in the future. The histologic damage would probably be a $\mathrm{T}$ cell-mediated response, not a $\mathrm{B}$ cell-mediated response. Therefore, although it is very interesting and worrisome, I would be more concerned about whether the patient needed future transplantation. We too have had the experience of performing transplantation in 4 patients who had had allografts in the neonatal period. We initially gave them immunoglobulin and were able to get the PRA down to about $5 \%$ to $10 \%$ before performing successful transplantation. That is what we do routinely now for those individuals who encounter this problem. That is a helpful adjunct to performing transplantation in patients with immunoreactive PRA panels.

Dr Edward Verrier (Seattle, Wash). This is a phenomenon that exists both in children and in adults. The problem is plaguing the Ross operation right now. In our series of about 100 patients, 3 patients have had to have their pulmonary autograft explanted and a new one implanted because of what appears to be a very strong inflammatory response in the conduit. Others who have performed the Ross operation have had similar small percentages of patients.
My first question is this: If you had access to the tissue, what would you look for to discern some of the issues related to what Vaughn stated and to prospectively then determine whether it is possible to predict which patients are going to get this response?

Second, if we could determine which patients will have that response, would it be worthwhile even within The Western Thoracic Surgical Association, where we have a number of resources, to conduct a multi-institutional study in which we would get access either to the preformed panels beforehand or to tissue and then be able to look at it in a more systematic fashion? This problem has a big impact not only on the tissue that we use in children but also increasingly in adults.

Dr Shaddy. Are you referring to explanted tissue?

Dr Verrier. Yes. If you remove the right ventricular-pulmonary artery homograft to implant another homograft, you have access to that tissue. We are looking at such tissue experimentally right now with a group of immunologists at the University of Washington in an attempt to discern anything unique about that histologic inflammatory response that would help us learn how to treat it. We still would not necessarily be able to predict who will have the response, because only a relatively small percentage of patients actually lose the allograft. However, on the basis of your data, there is an ongoing immunologic phenomenon that we need to further elucidate.

Dr Shaddy. As a nonimmunologist, I would first look for evidence of cellular infiltration, as we would do in a piece of a biopsy specimen from the heart. Also, we would look at B cell-mediated responses, including immunoglobulin, complement, and evidence of immune reaction in the vasculature and in the microvasculature on the grafts. We have not had an opportunity to do that. Others have looked at these grafts longer and claim there is no inflammatory response, so I suspect we would need to look for evidence of inflammatory or antibody-mediated responses as well. An even more intriguing approach would be to take some of the allograft that is being implanted and to somehow preserve, grow, or immortalize those cells. It may then be possible to look at the interaction of the allograft tissue and the patient's serum over time to see which patient is reacting against that piece of allograft that is now implanted in the patient. It might then be possible to predict who is going to have allograft dysfunction and an immunologic response and who may not. 